\title{
Valores y storytelling en los fashion films. El caso Tender Stories (2014-2017), de Tous
}

\section{Values and storytelling in the fashion films. The case Tender Stories (2014-2017), by Tous}

\author{
Méndiz Noguero, A., Regadera González, E. y Pasillas Salas, G. ${ }^{1}$ \\ Recibido: 29-05-2018 - Aceptado: 25-07-2018 \\ DOI: https://doi.org/10.26441/RC17.2-2018-A14
}

\begin{abstract}
RESUMEN: La comunicación de las marcas de moda configura su identidad a partir de los valores corporativos que son proclamados en su publicidad. La actual tendencia al storytelling potencia aún más la importancia de los aspectos inmateriales, pues las campañas narrativas promueven valores más que productos y ofrecen historias más que argumentos. Con la irrupción de los fashion films, las marcas de moda se han volcado en una comunicación emocional y narrativa: los productos quedan en segundo plano y los valores y el storytelling pasan a ser el eje vertebrador del discurso. En este artículo analizaremos la serie de fashion films Tender Stories (2014-2017), de la casa joyera Tous, cuyas historias desarrollan el concepto del amor. Para ello, utilizaremos el análisis fílmico que propone García-Noblejas ("primeras y segundas navegaciones") para descubrir cómo concibe Tous el amor en las diversas relaciones (noviazgo, matrimonio, relación padres-hijos) y cómo lo proclama en su storytelling.
\end{abstract}

Palabras clave: valores; storytelling; películas de moda; branded content; identidad corporativa; tender stories.

\begin{abstract}
Communication of fashion brands shapes their identity according to the corporate values shown in their advertising. The current tendency of storytelling highlights the significance of immaterial aspects, since narrative campaigns promote values rather than products and offer stories rather than arguments. With the emergence of fashion films, fashion brands have turned to emotional and narrative communication: while products remain in the background, values and storytelling become the backbone of the discourse.

In this study, we will analyze the series of fashion films Tender Stories (2014-2017), from the jewelry firm Tous, whose stories focus on the concept of love. For this, we will use the film analysis proposed by García-Noblejas ("first and second navigations") to discover how Tous conceives love in various relationships (courtship, marriage, parent-child relationship) and how the brand conceives it as a corporate value within its storytelling.
\end{abstract}

Keywords: values; storytelling; fashion films; branded content; corporate identity; tender stories.

1 Alfonso Méndiz Noguero es Doctor en Comunicación Pública por la Universidad de Navarra, Decano y Catedrático de Publicidad en la Facultad de Ciencias de la Comunicación de la Universitat Internacional de Catalunya. amendiz@uic.es, http://orcid.org/0000-0003-4450-1272

Elisa Regadera González es Doctora en Comunicación por la Universidad CEU Cardenal Herrera y Vicedecana y Profesora de Relaciones Públicas en la Facultad de CC de la Comunicación de la Universitat Internacional de Catalunya. eregadera@uic.es, http://orcid.org/0000-0002-1793-8105

Gabriela Pasillas Salas es Graduada en Comunicación Audiovisual por la Universidad de Navarra y Master en Artes Escénicas por la Universidad Complutense. gpasillass@gmail.com, http://orcid.org/0000-0002-5252-0804 


\section{Introducción}

La gestión de la comunicación está cada vez más presente en la vida de las marcas, no sólo con el objetivo de potenciar las ventas -algo más propio del marketing-, sino con una finalidad reputacional y de carácter transversal, procurando que su identidad corporativa esté presente en todas las fases y procesos. En un mundo global donde distintas corporaciones introducen en el mercado productos y servicios similares, las empresas compiten entre sí procurando marcar la impronta de su identidad en el público, lo que implica "la dialéctica de la diferencia: el ser o el organismo que es idéntico a sí mismo es, por tanto, diferente de todos los demás" (Costa, 2018, p. 360). Esta función identitaria de las marcas se fue amplificando en el último cuarto del S. XX con la idea innovadora de que todas las manifestaciones de la empresa deben trasladar los signos de su identidad no sólo al diseño gráfico (de los productos o de la publicidad), sino abarcar también de forma integral otros aspectos como el diseño arquitectónico, industrial, etc.

Cuando tratamos de definir la identidad corporativa de una marca procuramos reconocer en ella diversos elementos intangibles: lo que la empresa es (su misión, visión y valores); lo que la empresa hace (la actividad principal alrededor de la cual gira su sistema productivo y relacional); y lo que la empresa dice o/y expresa de sí misma (cómo se muestra, comporta y hace reconocer por sus públicos, realizando lo que dice).

Pero no se trata sólo de que el público identifique y diferencie unos pro- ductos, sino de atraer y conservar a los compradores, asegurar la propia originalidad y autenticidad, etc. Lo que existe para los clientes no son conceptos, sino "vivencias y experiencias, como por ejemplo satisfacción, confianza, adhesión -a esa marca- e incluso imagen, como una certidumbre que incluye esta clase de valores" (Costa, 2018, p. 364). Estos elementos identitarios, plasmados por las empresas a través de imágenes y comportamientos, son los que producen la diferenciación entre unas marcas y otras, contribuyendo a su posicionamiento en la mente de los consumidores. Dichas características -transmitidas a través de su comunicación- llegan a conformar un imaginario o estructura mental en los stakeholders que se traduce en una capacidad de influencia en sus comportamientos, llegando incluso a modificarlos (Apolo y otros, 2017).

Estos procesos de comunicación de las empresas en general son especialmente relevantes para las marcas de moda, que operan en un mercado muy competitivo donde las tendencias y la innovación evolucionan a gran velocidad. Además, pocos consumidores se identifican tanto con un producto como lo hacen los consumidores de moda: "en nuestra sociedad el vestido y el complemento forman parte, sin lugar a dudas, de la propia identidad de las personas" (DíazSoloaga, 2007, p. 29). Por este motivo, la administración estratégica de los elementos intangibles de una marca juega un papel esencial en la configuración de su identidad: "la imagen, la personalidad y la reputación de las marcas de moda se construyen en gran medida 
mediante su estrategia de comunicación" (Martínez, 2017, p. 147).

En este artículo pretendemos estudiar cómo las marcas de moda transmiten los valores que conforman su identidad, comunicándolos a través de un storytelling especial, propio de los fashion films. Para ello, analizaremos un caso emblemático: la serie Tender Stories (2014-2017) de la casa Tous, que ha posicionado la marca en torno al valor y al concepto de ternura-amor. Utilizaremos con este objetivo el análisis audiovisual que propone García-Noblejas (2004), basado en las "primeras y segundas navegaciones". Con base en ese análisis, trataremos de averiguar si el amor del que nos habla Tous en Tender Stories, -a pesar de discurrir en relaciones afectivas muy diversas: marido y mujer, padre e hija, novio y novia- presenta de forma recurrente unas notas características o esenciales que definen su principal valor de marca.

\section{Marco teórico}

\subsection{Comunicación de intangibles y branded content}

Los principales elementos constitutivos de la comunicación corporativa que se acaban de mencionar articulan la construcción y gestión integral de la vida de una marca. Su identificación mental parte de la representación de su "capital simbólico", seguida de su manera de contar lo que es y lo que comunica, para después armonizar atributos y direccionarlos hacia el aprovechamiento de una ventaja competitiva (Apolo y otros, 2017).

Si dirigimos una mirada hacia la histo- ria reciente de la publicidad, veremos que "el sector de la comunicación ha evidenciado que las fórmulas convencionales como las tasas de publicidad en televisión, radio, revistas y periódicos, cine, vallas publicitarias e incluso Internet, han sido superadas en inversión por la comunicación no convencional" (Díaz-Soloaga y García, 2016, p. 46). Es una realidad también "que los canales de comunicación tradicionales han demostrado su eficacia durante años, pero las marcas también se han dado cuenta de que no pueden ignorar las transformaciones radicales en el escenario actual de las comunicaciones" (Khan, 2012, p. 236).

Ante este panorama, el saturado mercado publicitario -caracterizado por la fragmentación de audiencias y canalesha evolucionado atendiendo a las demandas de entretenimiento audiovisual de los usuarios. En un primer momento, comenzó apostando por la integración de las marcas en las películas y series de televisión: el denominado product placement o emplazamiento de productos (Méndiz, 2007). Si el público cambia de canal en las franjas publicitarias, o se muestra reticente a las fórmulas invasivas basadas en la interrupción -como el spot o el publirreportaje-, el mercado decidió que era mejor integrar los productos y las marcas en contextos lúdicos que atraen de por sí al espectador. En una segunda fase, el mercado decidió ir más allá: en vez de integrar sus productos en espacios audiovisuales ajenos, se lanzó a crear sus propios espacios audiovisuales para el mejor lucimiento de sus productos. Aparece así el concepto branded content (o contenido de marca) como "una 
simbiosis entre publicidad y contenidos de entretenimiento, cuyo principal objetivo es atraer al público hacia los valores de una marca de forma atractiva y sugerente" (Ramos y Pineda, 2009, p. 729). De hecho, "las marcas han empezado a crear sus propios contenidos impregnados de sus valores y del universo de marca que el público está interesado en ver y compartir" (Arbaiza y Huertas, 2018, p.10).

Uno de los primeros casos fue el de BMW, que en el año 2000 puso en marcha una productora (BMW films) para la creación de una serie de cortometrajes titulados "The Hire", en los que un vehículo BMW actuaba como protagonista: las carreras, las persecuciones y este tipo de secuencias mostraban las virtualidades del producto. No integraron su marca en una serie, sino que crearon la serie para su marca. Y esta serie, que contó con directores y actores de primera línea (Ridley Scott, David Fincher, Tony Scott, Gary Oldman, Madonna o Clive Owen) logró once millones de descargas en una época en que no existía Youtube y las descargas exigían varias horas de espera.

Con esta integración de publicidad y entretenimiento audiovisual, las marcas iniciaron una nueva estrategia: la de contar sus propias historias. Y es que el branded content había abierto el camino para un nuevo storytelling publicitario.

\subsection{El storytelling en la publicidad de moda}

Contar historias siempre ha sido una necesidad para el hombre. Frente a las máquinas, cuyo único objetivo es la transmisión de meros datos, los individuos tienen la capacidad de humanizar mensajes gracias a los sentimientos y la percepción personal. El hombre tiene la capacidad de dotar de atractivo el mensaje y de enriquecer de forma única lo que transmite.

También la publicidad fue desde el principio un arte de contar historias: historias breves, como el spot, que ponían en valor las virtudes de un producto. En ese sentido, el concepto de storytelling es tan antiguo como la publicidad, pero su uso para la construcción y difusión de identidad de marca es una tendencia reciente que ha crecido al amparo del branded content, pues éste ha creado la posibilidad de contar historias de marca de forma más sutil, más emotiva y más proclive a generar verdadera conexión con el público.

Desde luego, una historia resulta menos invasiva que una argumentación, y un relato de la marca, más entretenido y emotivo que un spot comercial: "La marca debe ser capaz de generar engagement más allá de la mera transacción comercial, y para ello, el storytelling a través de un discurso corporativo y publicitario transmedia va a posibilitar contar historias y experiencias amigables a través de diversos medios y aportar contenidos informativos o de entretenimiento" (Del Pino y Castelló, 2015, p. 108).

La comunicación necesita historias porque las marcas se dirigen a personas. No basta con ofrecer datos y beneficios, es necesario narrar, convertir el mensaje en una historia, para diferenciarse así del resto y empatizar con el público. 
Este desarrollo de un nuevo storytelling ha tenido una especial repercusión en las marcas de moda, porque ellas han descubierto una nueva manera de transmitir su identidad de marca. El storytelling es una técnica idónea para asociar determinados valores corporativos a relatos y personajes, con el fin de conectar con la parte emocional de sus públicos. Por eso genera engagement, pues la creación de historias a través de representaciones imaginarias contribuye a construir discursos que expresan mejor los valores corporativos y sus vínculos con el consumidor:

El proceso de creación de este tipo de contenidos [branded content] pasa por la elección de un contenido que interese a los públicos de la marca y crear una historia. Durante el desarrollo interesa tanto la calidad del contenido como la forma (...). El éxito del proyecto radica en la convergencia entre los valores de marca y el mensaje a transmitir; un mensaje que deberá estar conectado con el público objetivo y donde tenga cabida la posible integración de la marca (Garrido y Fernández, 2014, p. 38; el subrayado es nuestro).

En el caso de la industria textil, hay que tener en cuenta que "nadie en una sociedad como la de ahora puede escapar de la moda, ya que es un fenómeno totalizante" (Díaz-Soloaga. 2007, p. 44).

La moda es una industria que aúna creatividad y negocio, y está llena de glamour, tendencias y cambios. Así que el uso de la publicidad en su versión más emotiva y artística se ha convertido en asignatura obligatoria en las campañas de las principales casas de moda, que cada temporada compiten por ser las más aclamadas y reconocidas por el público. Las marcas necesitan de una narrativa y unos valores eternos, atemporales e inmutables, pero también buscan una nueva historia para cada colección.

Debemos tener en cuenta que "en el contexto mediático actual, las marcas están construyendo su storytelling apoyándose en estrategias narrativas procedentes del mundo audiovisual" (Méndiz y García, 2017, p. 351). Así, se podría comparar una marca con una serie de ficción, en la que esa "serie" (marca de moda) estaría compuesta por episodios de trama cerrada (productos), pero con una trama de fondo que uniría los capítulos de la temporada (storytelling y valores de la campaña) y otra trama general de fondo, que aunaría dichas temporadas (storytelling y valores de la empresa).

Por otro lado, se puede ver como en las sesiones de fotos para una revista (con títulos sugerentes como "Aventura tropical" o "Días de esquî") se reúnen estilismos que por sí solos pueden carecer de sentido, pero que en su conjunto cuentan una pequeña historia. Igualmente, en cada pasarela el equipo creativo busca la forma de que la colección cuente una nueva historia a través de la puesta en escena: ritmo, música, luces, escenografía y la forma que tienen de presentar las prendas las maniquíes.

\subsection{El fenómeno de los fashion films}

Este nuevo modo de concebir y desarrollar el storytelling publicitario es el que pone en escena el formato audiovisual 
de los fashion films. Se denominan así a las producciones "a modo de cortometrajes, al servicio de una marca, caracterizadas por un estilo comunicativo en el que predomina la belleza y la estética extremadamente cuidada del mensaje sobre el producto y/o la marca en sí mismos" (Del Pino y Castelló, 2015, p.118). Este nuevo tipo de branded content tiene como objetivo atraer la atención de las personas de forma natural y sin interrupción, proponiendo un cambio de actitud en el consumidor y convirtiéndose en un proveedor de contenidos que interesen al público:

A través de los fashion films las marcas de moda buscan interactuar con sus consumidores, invitándolos a participar de su universo de marca a través de relatos impregnados de valores que conectan con sus emociones. Relatos cuidadosamente realizados -que combinan arte, moda, música, cine y publicidad- con los que logran un engagement con el público, destacando la belleza y estética de la pieza audiovisual (Arbaiza y Rodríguez, 2018, p. 10).

El precedente más conocido de estas películas de moda puede encontrarse en los short films surgidos en la industria de este sector, asociados a la exhibición de las colecciones de temporada en París, principalmente para clientes estadounidenses, con una duración de entre 10-15 min (Leese, 1991). Estas sugerentes novedades coincidieron además con otro cambio quizás más importante que se produjo casi al mismo tiempo: el desfile de moda derivó hacia un teatro espectáculo que impresionó con fuerza al público, quien empezó a vivir expe- riencias multimedia y multisensoriales, comprendiendo el concepto y proceso creativo existente detrás de una colección (Uhlirova, 2013).

Con estos antecedentes, a comienzos del siglo XXI surge una nueva versión de las películas de moda "como resultado de la revolución digital, creando una forma diferente de expresión, arte, marca y fuerte conexión con las comunidades" (Díaz-Soloaga y García, 2016, p. 47). Podemos hablar ya -según las mismas autoras- de un fenómeno distinto, utilizado en la industria de la moda para producir proyectos audiovisuales creativos dirigidos y utilizados por las marcas del sector. Y en ellas, además, las audiencias online participan activamente a través de las narrativas transmedia, desplegando las historias contadas por las marcas en distintos canales y soportes (Scolari, 2013).

La interacción de estos tres elementos (imagen de marca, arte y storytelling) ha hecho de los fashion films un instrumento con capacidad de recrear una atmósfera audiovisual de alto standing: "como una nueva forma de representación de alto brillo, [...] que ha desafiado formas más tradicionales de los medios de la moda" (Khan, 2012, p. 236).

\section{La serie Tender stories, de Tous}

\subsection{El caso de estudio}

Tous, una prestigiosa casa joyera de origen catalán, tiene unos orígenes humildes y una historia entrañable. La empresa de la familia Tous-Oriol creció fiel a sus principios y supo aunar tradición y modernidad para convertir un pequeño taller relojero de Manresa en una empresa 
internacional. Con los años, el negocio se vio enriquecido con la incorporación de las hijas del matrimonio fundador, quienes impulsaron -sin perder su identidad artesanal- el crecimiento de la empresa y su expansión en los cinco continentes. Con casi cien años de historia (nace en 1920), esta firma de affordable luxury ha sabido ganarse el respeto de un sector presentando sus creaciones como símbolo del amor y la ternura.

En noviembre de 2014, Tous lanzó una nueva estrategia comercial que, hasta cierto punto, rompía con la tradición anterior. Inició una serie de fashion films bajo el título Tender stories, que asociaba las joyas de su empresa a bellas historias de amor. Los filmes fueron creados por la agencia de publicidad SCPF de Barcelona.

La serie funciona como un reclamo narrativo para el público en un doble plano. Por una parte, cada pieza es emitida primero en televisión de forma resumida y a modo de tráiler, lo que motiva que muchos espectadores acudan a los canales de la marca (web, redes sociales) para ver la historia completa. Por otra, cada película incorpora un cierto número de joyas de la marca, a modo de catálogo, que aparecen con naturalidad en el trasfondo del relato. Cada historia integra diversas joyas, pero éstas no molestan al espectador porque ceden siempre el protagonismo al relato de la marca.

$\mathrm{Al}$ mismo tiempo, la serie se ha diseñado en el marco de una narrativa transmedia (Rodríguez, Paíno y Ruiz, 2016), que abarca los tres grados de experiencia transmedia señalados por Guerrero (2014) y García y Heredero
(2015). Así, las historias se difunden primero en televisión y producen un primer salto del espectador a Youtube, donde son visionadas en su totalidad, lo que incrementa el número de visitas (transmedialidad observativa). Después, se publican también en las demás redes sociales, sobre todo Facebook, Twitter e Instagram, donde los consumidores pueden participar a través de comentarios, likes, o republicaciones (transmedialidad discursiva). Finalmente, los usuarios publican comentarios en webs y blogs propios, o proponen otros argumentos para continuar la serie (transmedialidad creativa). Con esto, el relato global de la marca se enriquece con aportaciones de la audiencia.

La primera de estas películas estuvo protagonizada por la modelo Georgie Hobday y el actor Will Chitty, y narraba la historia de amor de una joven estudiante con su profesor. Tras el lanzamiento del tráiler y los anuncios online y offline, el vídeo se convirtió en un auténtico hit, y en poco tiempo sobrepasó los 5 millones de visitas: actualmente acumula ya 7.3 millones de reproducciones y 425 comentarios de los internautas. En vista del éxito, Tous preparó para San Valentín un spin-off prolongando la historia del profesor.

En abril de 2015 Tous lanzó la segunda historia, esta vez centrada en el amor familiar. Un padre y su hija preparan con esmero una pequeña fiesta con motivo de la llegada de la madre al hogar. De nuevo el vídeo se hizo viral en Internet. Más de 4.3 millones de internautas lo vieron y dejaron 37 comentarios entusiastas. La Tender story $n^{\circ} 3$, a finales de noviembre de 
2015, llegó justo a tiempo de la campaña navideña. En ella, una chica joven visita París y recuerda con nostalgia su primera estancia en la ciudad, acompañada de su padre. El leit motiv del amor adquiere así una nueva dimensión: no es ya el amor en la pareja o en el matrimonio, sino que alcanza también a las relaciones paterno-filiales.

Con la cuarta entrega (abril de 2016), se incorporó a la serie la actriz Gwyneth Paltrow, que se ha convertido en la embajadora de la marca. Paltrow es aquí una joven esposa a la que vemos en distintas situaciones, mientras escucha diversas grabaciones de su marido. Al final descubriremos por qué nunca aparece su esposo en imagen. En el quinto filme (noviembre de 2016), Gwyneth Paltrow vive un peculiar encuentro amoroso con Nicholas Gleaves: una historia de casualidades, en la que comprendemos que el amor está predestinado en nuestras vidas. En la sexta cinta (abril de 2017), Paltrow protagoniza un tierno relato con su madre, cuya relación se alimenta cada día a pesar de la distancia. Y en la séptima entrega (noviembre de 2017), la actriz nos muestra su lado más misterioso. La conclusión de este relato (acumula 2.2 millones de visitas y 33 comentarios) es clara: podemos amar a una persona aunque no lleguemos a conocerla por completo, incluso aunque desconozcamos su pasado.

La serie continúa abierta. Dos veces por año (en noviembre, para la campaña de Navidad; y en abril, para el Día de la Madre), Tous da a conocer una nueva Tender story que es esperada con notable expectación por parte del público.

\subsection{Justificación del caso escogido}

La elección de estas fashion film como elemento de estudio obedece a un triple criterio. En primer lugar, el papel que adopta el producto (las diversas joyas de la casa Tous) como protagonista discreto, pero indiscutible, en cada una de las historias; lo que viene a ser un ejemplo paradigmático de branded content: "El producto aparece durante todo el fashion film y desempeña un rol importante dentro del relato, pues el producto funciona como un motor y permite el desarrollo de la historia" (Arbaiza y Huertas, 2018, p.25)

En segundo lugar, hemos escogido este ejemplo por la relevancia de la campaña en el panorama publicitario español y porque logró posicionar a la marca de una manera muy significativa. Como señala Quevedo (2016):

Los resultados fueron espectaculares. Por primera vez Tous aparece entre las 50 marcas de retail más importantes de Europa y una de las 150 de todo el mundo. Además, las visitas a la web se incrementan en un $58 \%$ en el primer mes, y Tous pasa a ser la marca № 1 en el top of mind y notoriedad publicitaria en España y Méjico, multiplicando por cuatro su presencia en Polonia. Las ventas aumentaron un $17 \%$ en España y un 15,2\% en el ámbito internacional (...). Las piezas audiovisuales consiguieron un total de 18 millones de visualizaciones en YouTube, multiplicando por siete los suscriptores, y en redes sociales se alcanzó un $15 \%$ más de seguidores en Facebook y un impacto potencial de 
7.150 .000 usuarios en Méjico y España a través de \#Tender Stories.

En tercer lugar, las fashion films de Tous han sido galardonadas en años sucesivos en varias categorías de los Premios Eficacia, otorgados por la Asociación Española de Anunciantes y por Scopen. En 2017 obtuvieron el Bronce a la Mejor Campaña Integrada, la Plata a la Mejor Campaña en Medios Propios y el Oro a la Mejor Internacionalidad. En 2016 y en 2015, obtuvo también la Plata a la Mejor Internacionalidad.

A esto hay que añadir que, con el giro de imagen, Tous ha sido reconocida por los críticos de moda como una marca joven, moderna e idónea para regalar. En pocas palabras, "la campaña ha conseguido actualizar y renovar el valor de la ternura y volver a conectar con la consumidora y con la esencia de marca, logrando identificación en los clientes actuales y aspiracionalidad y relevancia entre los no clientes" (Quevedo, 2016).

\section{Metodología de análisis}

Plantearnos cómo Tous presenta sus valores de marca en la serie Tender Stories supone entrar de lleno en el análisis de valores en publicidad. Este campo cuenta ya con una larga trayectoria gracias a los estudios de Richard Pollay (1983, 1986, 1990) que desarrolló una línea propia de análisis de contenido, basada en una sólida clasificación axiológica. Esto permitió la proliferación de estudios sobre los valores culturales que las marcas transmiten en mercados transnacionales, como el de Tous (Srikandath 1992; Wang 1997; Cheng 1997; Shao, Raymond \& Taylor
1999). En el ámbito de la publicidad española, la investigación se ha centrado en la promoción de valores y creación de estereotipos que influyen notablemente en las audiencias: Méndiz (1988, 2005), Alameda (2006), Núñez, Olarte y Reinares (2008) o Castelló, Ramos y Del Pino (2013).

Sin embargo, los fashion films escapan un poco a esas metodologías globales. $\mathrm{Su}$ estética cinematográfica y su estructura narrativa más próxima al cortometraje, pide un tipo de análisis más cercano a los estudios fílmicos. En concreto, y eludiendo otras perspectivas narratológicas (Booth 1978, Bettetini 2002, Chatman 1990, Ricouer, 2010), adoptaremos la noción de "sentido" tal y como la exponen García-Noblejas (1996, 2004) y Brenes (2011, 2016).

El sentido de un filme no es solo el asunto del que trata un relato (los celos, la venganza, la superación, la identidad), ni tampoco el punto de vista que se adopta sobre el asunto; ambas perspectivas configuran una "primera comprensión de las estructuras de la superficie de la trama narrativa", lo que García-Noblejas denomina "primera navegación” (2004, p. 52). El sentido tiene que ver con el principio rector del relato, que estructura y da coherencia a los hechos allí narrados y que, precisamente porque señala algo profundamente humano, provoca en nosotros una identificación; esa aplicación del texto es la "segunda navegación", que "responde a un análisis hermenéutico de las estructuras poéticas profundas del texto" (p. 52). De este modo, cuando vemos películas o series televisivas, 
vivimos muchas vidas: aprendemos sobre los grandes temas (la familia, el noviazgo, la libertad, el amor) porque en ellas reconocemos aspectos vitales de la existencia humana.

Para descubrir el "sentido" que anida en la serie Tender stories, llevaremos a cabo una metodología de análisis de contenido en torno a los temas que plantea cada filme y el conjunto de la serie. Un análisis de tipo hermenéutico basado en la doble navegación que propone García-Noblejas.

La hipótesis de partida es que, en esta serie, Tous quiere asociar su imagen de marca a un valor de referencia: el amor. Éste es el tema central de todas las Tender stories. El objetivo que pretendemos es identificar qué características prevalecen en los capítulos de la serie y son, para la casa Tous, las definitorias de toda relación amorosa. La metodología, como ya se ha dicho, consiste en un análisis de contenido que se articula en un doble plano:

a) en una primera navegación, analizaremos las notas del amor que se deducen de cada uno de esos relatos. Para ello, atenderemos a tres niveles de significación: el plano narrativo, el plano formal (realización, montaje, cromatismo y registro sonoro) y el sentido global de la historia.

b) en la segunda navegación, trataremos de concluir qué características esenciales del amor permanecen de manera constante -como sustrato común- en todas esas historias. Esta segunda visión, que vertebra y da continuidad a la serie, supone una visión más profunda e interesante, porque apunta al sentido que Tous quiere dar a su concepto de amor y de ternura, como valor intrínseco de su marca.

\section{1. Primera navegación: historias de amor en Tender stories}

Tender story $n^{\circ} 1$. El primer relato desarrolla la historia de amor de una joven estudiante con su profesor, desde la fascinación que ella siente en las clases y la primera conversación en su despacho, a la creciente confianza en el trato, el progresivo enamoramiento y las primeras salidas. La historia sufre un repentino giro cuando el profesor visita a los padres de ella, que le reciben con cierto recelo. Esa visita les hace caer en la cuenta de las barreras por su diferencia de edad, y el romance termina con una separación amigable que no apaga el amor: permanece en la mutua transformación que ese amor ha dejado en sus vidas.

Desde una perspectiva formal, la realización nos traslada a la visión de la chica, que se convierte así en el foco narrativo. Desde su punto de vista, vemos primero el aula con el profesor al fondo, después el retrato que dibuja en su cuaderno, y finalmente los primeros planos de él, que sugieren su admiración. El montaje, a través de planos cortos, muestra la progresión del romance, y culmina con un plano detalle en la cafetería, cuando la mano de ella roza la del profesor. El color visualiza la diferencia de edad: lo vemos en los atuendos de uno y otra, pero sobre todo en la visita a la familia de ella: ahí descubre el profesor que el padre lleva una corbata del mismo color y dibujo, y eso le hace comprender 
que tiene edad para ser literalmente su padre.

Aquí, el amor se nos presenta en su vertiente más platónica, como un afecto profundo que llena de ilusión las vidas de quienes se aman. Un afecto tan hondo que supera incluso las diferencias de edad, cultura y clase social, aunque éstas parezcan un serio obstáculo para los demás. El final del filme deja la resolución en el aire: la presión social provoca su separación, pero el amor permanece en ellos para siempre en el afecto que les une.

Tender story $n^{0} 2$. La historia comienza a las $7.45 \mathrm{am}$, con el despertar de un padre y su hija, y la alegría y con que ambos preparan un espléndido desayuno. Se les ve ilusionados, tiernos. Se visten con las mejores galas. Y cuando parece que van a celebrar algún aniversario entre ellos, resulta que preparan... iel maravilloso encuentro con la madre! A las $8.00 \mathrm{~h}$ en punto la madre entra por la puerta después de una larga jornada de trabajo en el hospital, en horario nocturno. Pronto descubrimos que, no obstante las apariencias, ese encuentro festivo se produce todos los días. Nada hay de rutina en ese gozoso recibimiento, en el que padre e hija colman de abrazos y cariño a la madre cansada.

La fotografía del filme refuerza la visión nostálgica que impregna el relato. Comenzamos con una panorámica sobre la cama de matrimonio que termina sobre el lado vacío de ella. El sonido del despertador nos lleva a la mesilla, donde está la foto de la madre. Ambas imágenes suscitan en el espectador la idea de ausencia (¿habrá fallecido?). Por contras- te, los colores son alegres y cálidos, y la puesta en escena tiene un tono festivo, que hace presagiar el final feliz; por eso el desenlace (la irrupción de la madre) no sorprende al espectador. Sobre todo, por la interpretación enamorada de padre e hija, que dan a la preparación de la mesa un significado romántico.

También el tiempo actúa como eje temático. Al principio suena el despertador, al entrar la madre oímos el cucú, y el desayuno termina cuando la hija mira su reloj. Sólo pueden verse $15 \mathrm{mi}$ nutos al día, porque padre e hija tiene que salir corriendo, pero eso mismo les lleva a aprovechar el tiempo con una espléndida cena-desayuno. En ese tiempo se miran, sonríen y llenan el espacio con pequeños detalles. A las $8.15 \mathrm{~h}$ se produce la desbandada. La madre se prepara para dormir; pero antes, como una alegre rutina, mira por la ventana para ver como su hija, desde la calle, le lanza el beso cariñoso de todos los días.

Esta fashion film es un emocionado elogio del amor familiar; un amor esperado con ilusión cada mañana, que por eso mismo no acontece solo en los aniversarios y en los grandes momentos, sino que -cuando el amor está vivo- sucede cada mañana. También por eso no se manifiesta en grandes obsequios, sino en los detalles. En la sonrisa, en la mirada, en ese cogerse la mano o en ese beso que es igual todos los días.

Tender story $n^{-}$3. Sobre bellas imágenes de París, la protagonista de este relato va contando su inolvidable viaje a la capital parisina cuando tenía 8 años, acompañada de su padre. La vemos en distintos lugares, con distintos vestidos y 
accesorios... y con distintos novios. A cada uno le cuenta una parte de la historia: "Estuvimos los dos solos durante tres días mágicos", "Aún guardo algunas fotos", "Siempre que vengo, recuerdo ese increíble fin de semana"... El regalo de ese viaje ha quedado para siempre en su memoria; pero, a la postre, se revelará como un triste presagio: ninguna de sus relaciones futuras logrará perdurar. De ahí la confesión que hace a su última pareja: "Mi padre me dijo: 'Quería que vieras París con el único hombre que te querrá siempre, pase lo que pase"”.

El análisis formal nos hace descubrir varios elementos significativos. Por una parte, y a diferencia de los filmes anteriores, la voz cobra protagonismo y relieve. Frente a una sucesión de imágenes variadas y típicas (el Sena, la Torre Eiffel: una imagen "postal" de París), la voz de ella se convierte en hilo conductor del relato, hilvanando un discurso amoroso que solo entenderemos al final. Por otra, la música -siempre decisiva en Tender Stories-adquiere aquí relieve destacado, pues modula los vaivenes emocionales del recuerdo y ambienta perfectamente la acción: desde el primer acorde, una balada francesa nos sitúa en la capital francesa y anuncia una preciosa historia de amor perdurable.

El análisis global nos permite apreciar ese elogio del amor paterno, que dura siempre, que perdona y olvida, que resurge en cada momento de dificultad; pero que, en esta historia, tiene también un regusto de tristeza: por su estilo de vida, ella parece condenada a la soledad, y solo es confortada y acompañada por el permanente recuerdo del padre que -intuimos- ya no está en este mundo. Su recuerdo y su amor es lo que ella desea revivir en sus frecuentes viajes a la capital francesa, para superar su permanente ausencia. La idea del amor eterno planea de nuevo en este filme, pero centrada en el amor de padre, que sí es para siempre.

Tender story $n^{0} 4$. Una mujer joven escucha una voz en off que suena durante todo el relato, intentando "adivinar" los sucesos del día que comienza. Mediante el pitido de un despertador y un "buenos días, Alice" que subraya el paso del tiempo, la voz en off trata de anticipar lo que va a ocurrir: recuerda que "hoy" es el cumpleaños de su madre, pronostica el horóscopo de Alice ("tendrás un día increíble, te tocará la lotería”), y durante 3 días seguidos intenta predecir el parte meteorológico -que siempre le parecerá optimista, a pesar de las imágenes lluviosas-. Finalmente llega un día especial, un aniversario de ambos en el que el narrador recuerda perfectamente el vestido que ella llevaba. Después le pide que busque en una estantería alta, donde ha dejado un regalo para ella: un collar a juego con el vestido. El relato termina con un "Te quiero, un beso".

De nuevo el registro sonoro cobra protagonismo en este relato. Como en la historia pasada, la voz dirige la narración y reconstruye el pasado. La interpretación de ella (Gwyneth Paltrow, por primera vez) es la perfecta réplica del discurso narrado: la vemos nostálgica, emocionada, enamorada... Ante cada uno de los detalles de él, Alice corresponde con una sonrisa de complicidad y agradecimiento. De nuevo la idea de ausencia vertebra la 
puesta en escena, porque los colores apagados y los gestos de la actriz muestran una distancia física entre ellos, pero una distancia que no reduce el amor, sino que lo hace madurar. La música, una vez más, expresa y modula la emoción de esos recuerdos. Y también el tiempo, como eje temático, se visualiza aquí en relojes, calendarios y referencias al día en curso.

El espectador, que empatiza con el relato desde el principio y se pone en la piel de Alice, no entiende hasta el final el sentido de la historia. La cámara nos muestra al fin que la voz proviene de una cinta de cassette que Alice saca del reproductor y guarda en su funda, mostrando toda una estantería llena de cintas, ordenadas por días. Cuando ya hemos quedado impresionados por la idea feliz del marido ausente -de cómo ha pensado en Alice tanto tiempo y anticipadamente-, una panorámica nos muestra unas fotos en las que él aparece vestido de astronauta. Es aquí cuando todo el relato cobra sentido y da razón de todo lo que hemos visto: su amor por Alice es tan grande que ha dejado cintas grabadas para cada día que permanecerá en el espacio, con el fin de acompañarle y tener, cada día, un detalle con ella.

Tender story $n^{0} 5$. La historia tiene como escenario principal una cafetería donde los protagonistas -Kate y Peter- coinciden cada día a la hora del desayuno, aunque nunca llegan a conocerse. A veces, en algún extraño momento, sus miradas se cruzan, pero algo se interpone siempre en la visión: un camarero que pasa, un perchero en la esquina... El narrador nos dice lo diferentes que son: Kate es moderna y sensible, Peter clásico y racional; ella es profesora de violín, y él diseña zapatos. Pero, al mismo tiempo, la voz nos hace descubrir los rasgos que tiene en común: su gusto por las flores, su amor a una misma canción, su misma película favorita... Por eso suspira al fin: "iAy, si sus miradas se cruzaran! Se enamorarían al instante, porque están hechos el uno para el otro". Pero nunca se ven, ni se encuentran.

Los elementos formales (color, puesta en escena) nos hacen descubrir esa común afinidad. Los dos visten de azul en ocasiones señaladas, y los dos bautizaron a sus perros con el nombre de su película favorita. La voz del narrador -esta vez fuera de la escena- pone de relieve su semejanza de espíritu por encima de toda diferencia: ella no lo sabe, pero sus zapatos preferidos fueron diseñados por el tatarabuelo de Peter; y Kate tiene tatuado en su muñeca un verso de la canción favorita de él. Los dos tienen pasión por la fruta: Kate lee un libro para aprender a cultivarla, y Peter otro para saber conservarla. Sus accesorios son distintos (pulseras en ella, reloj en él), pero ambos son... de la marca Tous.

El espectador se siente involucrado por la historia y desea conocer el desenlace. Un pendiente de Tous rodando por el suelo es la excusa elegida por el guionista para que Kate se ponga de pie. Los perros de ambos ladran, y sus dueños pronuncian sus nombres respectivos: “iRobin!”, “iHood!”. La coincidencia en su película favorita (por fin lo descubrimos) hace que ambos se miren por primera vez. Entonces, Peter encuentra a sus pies el pendiente de Kate, y se lo ofrece. El destino ha provocado al fin ese 
encuentro, y en un instante ambos descubren, en la mirada, la afinidad con aquella persona que hasta entonces desconocían. El amor puede sobrevenir en un momento y descubrir al ser humano que estaba predestinado para mí.

Tender story $n^{\circ}$ 6. Las nuevas tecnologías hacen posible esta delicada historia de amor filial. Claire y su madre viven separadas por miles de kilómetros, pero siguen manteniendo una estrecha relación a través del Whatsapp, el Skype y la Tablet. La distancia entre Europa y América, con su diferencia horaria, queda anulada para estas dos mujeres, que comparten su día a día a través de dispositivos electrónicos. Durante la historia, el espectador vive junto a Claire la misteriosa actitud de su madre ante una fiesta a la que ha sido invitada y en la que quiere estar deslumbrante. Claire le aconseja en este punto, le compra los pendientes que tanto le ilusionan y continúa divertida por el suspense al que le tiene sometida. Finalmente, una conmovida Claire contempla en el Skype a su madre, vestida con un traje de novia, que le pregunta: "¿Qué? ¿Voy a ser la novia más guapa de mi boda o no?".

En el aspecto formal, la realización juega con el suspense. Ya la primera imagen es un rótulo, "The End", que sugiere el fin de una película romántica. Madre e hija lo contemplan con ojos llorosos, y comentan el final, como si estuvieran en la misma habitación. De repente, la imagen de la madre se esfuma: el wifi se ha caído y descubrimos que viven a ambos lados del Atlántico. Más tarde, el suspense sigue por la fiesta que prepara la madre, y culmina en el últi- mo plano. La hija mira su ordenador y muestra sorpresa: “iNo puede ser!”. Y solo en el contraplano vemos por fin a la madre vestida de novia. Por otro lado, los diálogos muestran la cercanía vital entre ellas, más allá de la distancia. Y, a la vez, percibimos su separación en los colores: alegres en Nueva York, apagados en Barcelona. La idea de la ausencia, común a toda la serie, está aquí presente en la interpretación de la hija. Cuando el wifi se cae, Paltrow exclama: "iTe echo tanto de menos!". Y sus gestos revelan la profundidad de ese afecto.

El análisis global evidencia que el amor no entiende de tiempo ni de distancia. La amistad entre madre hija supera todas las barreras y es capaz de superar todos los obstáculos. Todo esto hace que este filme sea un elogio maravilloso en el día de la madre. Porque el amor entre madre e hija es un afecto común a todas las culturas y a todas las épocas, y en este cortometraje se pone de manifiesto que, hoy en día y en un mundo tan veloz, las nuevas formas de comunicación pueden unir y estrechar lazos a pesar de la distancia.

Tender story $n^{-} 7$. Jack y Rebecca se conocen en una biblioteca, desde el primer minuto él queda intrigado por el medallón que ella lleva y del que no quiere hablar. Comienzan una relación, van a museos y visitan a los padres de ella por Navidad, pero a pesar de la confianza, Rebecca no quiere hablar del medallón por el que Jack siempre le pregunta. Una noche, y tras una pesadilla acerca del pasado amoroso de Rebecca, Jack entiende al fin que jamás podrá conocer ni cambiar el pasado de ella, pero que sí puede ser parte de su futuro. 
El aspecto formal del filme visualiza de nuevo la sensación de suspense, pero no sobre acciones futuras, sino sobre el pasado de ella. Del mismo modo, se visualiza la idea de ausencia, pero aquí en los pensamientos de él: comprende que ha estado ausente en la vida de ella y quiere ocupar esa vida y asumirla como si eso fuera posible o necesario para amarla. La puesta en escena -con los sueños angustiosos en la nieve y en el fuego- le hacen comprender que está equivocado. Para confirmarlo, le regala a su amada un medallón que ella combina con el otro: la imagen nos dice que ambas facetas de su vida pueden convivir juntas. También los colores del sueño tienen su importancia: el azul glacial simboliza la aparente frialdad de ella, mientras que el rojo ardiente alude a su obsesión casi demoníaca.

En esta historia, el espectador es testigo de cómo, a pesar del grado de confianza que pueda existir en la pareja, los secretos del pasado pueden existir, y no deben separar o importunar a los que se aman. En una relación es importante entender al otro, respetar su espacio y dar el tiempo necesario para que se abra. Sin embargo, también es posible que dos personas plenamente unidas puedan tener sus pequeños y propios dominios en los que el otro no ha de interferir. Es, pues, una historia que nos habla del respeto y de la comprensión, y que termina con el feliz pensamiento de que lo más importante en el amor es olvidar el pasado para construir un futuro común.

\subsection{Segunda navegación: el sentido del amor en Tender stories}

Como planteábamos en la exposición de la metodología, en esta "segunda navegación" trataremos de indagar en las características del amor que subyacen a todos los relatos la serie Tender stories. En esas características encontraremos el "sentido" de esos relatos (más allá del tema de fondo) y, en consecuencia, el valor que la casa Tous quiere asociar a su imagen de marca. Esas características pueden resumirse en 5 puntos:

1. Amor romántico. En los siete relatos analizados el amor es presentado siempre como un afecto maravilloso, romántico y no pocas veces platónico, que cambia nuestras vidas. No hay, en estos filmes, nada pasional ni sexual. Todo esto queda en un segundo plano, como algo secundario frente al afecto sincero. El amor auténtico (tanto en la pareja como en el matrimonio o en la relación padres-hijos) se plasma en los detalles: en las emociones y expresiones de afecto que revelan la presencia del amado en el amante: el cariño con que padre e hija preparan el cotidiano desayuno (n⿳⺈ 2); el recuerdo emocionado del viaje a París con su padre (no 3); la ternura con que el marido astronauta deja un mensaje cotidiano para su esposa (no 4); la generosidad con que una hija acompaña todos los días a su madre a más de 10.000 Kms. (no 6); o la aceptación del pasado amoroso de la amada para buscar un futuro juntos (no 7). En todas estas historias el amor es siempre romántico y afectuoso, generoso y entregado.

2. Relación que supera los obstáculos, con vocación de perpetuidad. En todas las historias el amor es un afecto que supera las dificultades y tiene vocación de perpetuidad. Esto sucede incluso en la historia 
n⿳0 1 , donde la relación profesor-alumna supera los perjuicios y las diferencias entre ellos (de edad y de cultura) y prevalece de alguna forma también después de la separación. Sobre todo se percibe en las historias familiares. Por ejemplo, en la n 2 , donde marido y mujer sólo pueden verse 15 minutos al día, el amor prospera, se hace nuevo cada mañana -a pesar del poco tiempo disponible-y justamente se hace eterno en las pequeñas manifestaciones de afecto. También lo vemos en la historia $\mathrm{n} \mathbf{0}$, donde la distancia cósmica no es óbice al amor entre ambos esposos; y en la $n \underline{0} 6$, donde la distancia geográfica es vencida gracias a los dispositivos y a la tecnología. También el recuerdo del viaje a París (n⿳0 3) se hace eterno en la memoria de la hija, y supera todas las barreras que levantan el tiempo y el olvido. Y el amor que un día surge en la librería (no 7 ) tiene vocación de eternidad a pesar de no conocer el pasado de la otra persona: es el futuro -el proyecto común que les une- lo que da permanencia a ese afecto.

3. Prevalencia del amor familiar (en lo cotidiano). Este ámbito amoroso es, en la serie, el más frecuente, el más elogiado, el más íntimo y sincero. De alguna manera, es el que se pone como modelo para todos los demás. Ninguna historia habla de situaciones extremas, todas podrían ocurrir muy cerca de nosotros, en la intimidad familiar y con una total normalidad. Por ello, nos resulta fácil entender que ese amor familiar puede tener la oportunidad de brillar y crecer en las situaciones más ordinarias de cada día. Un ejemplo claro es el detalle de puntualidad y cariño que tienen cada mañana el padre y la hija con su madre; se da entender que ella tiene siempre el turno de noche, y no por ello su familia trata con desidia esos minutos que tienen para verse; muy al contrario, preparan con ilusión ese pequeño desayuno familiar que tiene algo de festivo. Otro ejemplo es el hermoso detalle que ha preparado el marido astronauta: para cada día que estará ausente, ha dejado una grabación matutina para acompañar a su mujer. Ambos son ejemplos maravillosos de amor familiar en lo cotidiano.

4. Permanencia del amor padres-hijos. Es un amor que permanece siempre, entre padre e hija (no 3) y entre hija y madre (n⿳⺈ 6). Las protagonistas de ambas historias son mujeres que rondan los 35 años, que han vivido y madurado, y han tenido muchas experiencias en la vida. A pesar de todo, cuando se trata de pensar en la figura del padre o madre, sale de su interior la niña que llevan dentro para mirar con ternura los recuerdos (n⿳⺈⿴囗十一) o las circunstancias ( $\mathrm{n}-6$ ). Porque esos recuerdos y circunstancias están relacionados con la persona que les ha dado la vida, a la que admiran y agradecen todo lo que son. El amor paterno-filial cobra protagonismo, sobre todo, en la historia $\mathrm{n} \mathbf{0} 3$, donde la relación entre un padre y su hija se convierte en ejemplo y medida para las relaciones amorosas de la protagonista. Ella busca en su pareja el mismo afecto, respeto y devoción que su padre le enseñó que merecía de un hombre. Por otro lado, el amor sin fronteras que permite que una hija y su madre sigan estando unidas a pesar de la distancia, es el tema de la historia $\mathrm{n} \mathbf{0}$. Por tanto, se puede decir que 
una idea transversal de las Tender Stories, con respecto al amor que existe entre padres e hijos, es que se trata de un afecto eterno, atemporal y fuerte, superior a todas las adversidades.

5. Amor es, ante todo, hacer feliz al otro. En la mayoría de las historias se percibe que el que ama piensa en cómo hacer feliz al otro. La historia no 1 muestra un amor sincero entre profesor y alumna (comparten ratos juntos, aficiones y salidas), que quiere lo mejor para el otro, también cuando descubren que su relación no es posible, y procuran no hacerse daño en el momento de la ruptura (baile final con el que se separan). La historia $\mathrm{n}-2$ muestra que a veces se dispone de poco tiempo para estar en familia (horarios laborales dispares), pero el amor resuelve las cosas con ingenio; y ante el esfuerzo de padre e hija para preparar el desayuno, la madre se esfuerza también -a pesar de su cansan- cio- por disfrutar de esos minutos juntos. En la story no 3 una hija recuerda todos los detalles que su padre tuvo con ella cuando le llevó a París. Ese amor le hizo muy feliz y es el motivo por el que se lo cuenta a sus parejas. La fashion film no 4 muestra cómo el amor verdadero supera la distancia y el tiempo con audacia e ingenio para pensar en el otro: como se ve en esa diaria cinta de cassette. En la no 6 una madre pide consejo a su hija en la distancia, para comprar un complemento importante para una boda. La hija, a pesar de su mucho trabajo, piensa en la madre y busca con ilusión lo que le pide, sabiendo que la hará feliz.

Todas estas características que advertimos en la segunda navegación de la serie Tender stories pueden quedar reflejadas en la siguiente tabla. Entre paréntesis indicamos aquellas características que sólo parcialmente se reflejan en el relato.

Tabla 1. Características del amor en las Tender stories, de Tous

\begin{tabular}{|l|c|c|c|c|c|c|c|}
\hline & № 1 & № 2 & № 3 & № 4 & № 5 & № 6 & № 7 \\
\hline 1. Amor romántico & $\mathrm{X}$ & $\mathrm{X}$ & $\mathrm{X}$ & $\mathrm{X}$ & $\mathrm{X}$ & $\mathrm{X}$ & $\mathrm{X}$ \\
\hline 2. Supera los obstáculos, vocación de eternidad & $(\mathrm{X})$ & $\mathrm{X}$ & $(\mathrm{X})$ & $\mathrm{X}$ & $(\mathrm{X})$ & $\mathrm{X}$ & $(\mathrm{X})$ \\
\hline 3. Prevalencia del amor familiar (en lo cotidiano) & & $\mathrm{X}$ & $\mathrm{X}$ & $\mathrm{X}$ & & $\mathrm{X}$ & \\
\hline 4. Permanencia del amor padres-hijos & & $\mathrm{X}$ & $\mathrm{X}$ & $\mathrm{X}$ & & $\mathrm{X}$ & \\
\hline 5. Amor es, ante todo, hacer feliz al otro & $(\mathrm{X})$ & $\mathrm{X}$ & $\mathrm{X}$ & $\mathrm{X}$ & $(\mathrm{X})$ & $\mathrm{X}$ & $\mathrm{X}$ \\
\hline
\end{tabular}

Fuente: Elaboración propia

\section{Conclusiones}

La ancestral necesidad del hombre de contar y escuchar historias encuentra hoy un cauce privilegiado en el denominado storytelling: un modo de expresar, significar y elaborar discursos a través de la construcción de relatos. En la publicidad de las marcas de moda, esa tendencia narrativa se plasma hoy en las fashion films, relatos -al mismo tiempo cinematográficos y publicitarios- que muestran los valores fundamentales de una marca. 
En el caso de estudio -la serie Tender Stories (2014-17)- hemos comprobado cómo la casa Tous construye el relato de su marca asociándola al valor de la ternura y el amor. En nuestro análisis, la "primera navegación" nos ha llevado a identificar las notas del amor de cada relato en un triple plano: narrativo, formal y significado global; después, en una "segunda navegación", hemos constatado las características que subyacen a toda la serie y que, para la casa Tous, definen la relación amorosa. Estas características son:

1. Prevalencia del amor romántico sobre cualquier otro tipo de relación: pasional, sexual, etc. El amor auténtico, tanto en la pareja como en la relación padres-hijos, se plasma en expresiones de afecto cotidianas que reflejan la presencia del amado en el amante.

2. El amor es una relación que supera los obstáculos y tiene vocación de perpetuidad. No es un afecto que dura unos días o unas semanas, sino una donación permanente que supera, si es necesario, la distancia geográfica o temporal, sobre todo en las circunstancias diarias.

3. El amor familiar es presentado como paradigma de toda relación afectiva. El amor más frecuente, el más elogiado y sincero es, en todas las historias, el que se presenta en la intimidad familiar.

4. Permanencia del amor materno/ paterno-filial. En el trasfondo de varios relatos, el afecto de un padre o una madre hacia su hija se nos presenta como un sentimiento que perdura siempre, más allá incluso de la muerte. Se convierte en el ejemplo y medida para todas las relaciones amorosas.

5. El amor consiste en hacer feliz al otro. Más que el sentimiento de plenitud o de satisfacción, lo que da sentido a la relación amorosa es constatar la felicidad del otro precisamente en esos momentos de compañía o intimidad.

En torno a estos cinco puntos, Tous construye el storytelling de la serie, que configura su discurso sobre el amor: un valor que, en la serie Tender Stories, se identificada con su imagen de marca.

\section{Bibliografía}

Alameda, D. (2006). Una nueva realidad publicitaria. La generación de valores corporativos en publicidad. Madrid, España: Laberinto Comunicación.

Apolo, D.; Báez, V., Pauker, L. y Pasquel, G. (2017). Gestión de Comunicación Corporativa: consideraciones para el abordaje de su estudio y práctica. Revista Latina de Comunicación Social, 72, pp. 521-539. DOI: 10.4185/RLCS-2017-1177en

Arbaiza, F. y Huertas, S. (2018). Comunicación publicitaria en la industria de la moda: branded content, el caso de los fashion films. Revista de Comunicación, 17(1), 9-33. DOI:10.26441/ RC17.1-2018-A1

Bettetini, G. (2002). La conversazione audiovisiva: problemi dell'enunciazione filmica e televisiva. Milano, Italia: Bompiani.

Booth, W. (1978). La retórica de la ficción. Barcelona, España: Bosch.

Brenes, C. S. (2011). The Practical Value of Theory: Teaching Aristotle's Poetics to Screenwriters. Comunicación y sociedad, 24(1), 101-118. Recuperado de https://www.unav.es/ 
fcom/communication-society/es/articulo.php?art_id $=380$

Brenes, C. S. (2016). Explorando el tema. La noción poética de "sentido" al servicio de la escritura de guion. Revista de Comunicación, 15, 166-182. Recuperado de https:/dialnet. unirioja.es/servlet/articulo?codigo $=5880408$

Castelló, A., Ramos, I. y Del Pino, C. (2013). El discurso publicitario en la crisis económica: nuevos valores y redes sociales, Historia y Comunicación Social, 18 (Esp), pp. 657-672. Recuperado de http://revistas.ucm.es/index.php/HICS/article/view/43997

Chatman, S. (1990). Coming to terms: The rhetoric of narrative in fiction and film. New York, EE. UU.: Cornell University Press.

Cheng, H. (1997). Toward an Understanding of Cultural Values Manifest in Advertising: A Content Analysis of Chinese Television Commercials in 1990 and 1995. Journalism and Mass Communication Quarterly, 74(4), 773-96. DOI: 10.1177/107769909707400408.

Costa, J. (2018). Creación de la imagen corporativa. El Paradigma del Siglo XXI. Razón y Palabra, Vol. 22, Enero-Marzo, pp. 356-373.

Del Pino, C. y Castelló, A. (2015). La comunicación publicitaria se pone de moda: branded content y fashion films. Revista Mediterránea de Comunicación, 6(1), pp. 105-128. doi. org/10.14198/MEDCOM2015.6.1.07.

Díaz-Soloaga, P. (2007). Valores y estereotipos femeninos creados en la publicidad gráfica de las marcas de moda de lujo en España. Anàlisi, 35, 27-45. Recuperado de https://dialnet. unirioja.es/servlet/articulo?codigo $=2592376$

Díaz-Soloaga, P. y García, L. (2016). Fashion films as a new communication format to build fashion brands. Communication E Society, 29 (2), pp. 45-61. Recuperado de https://www. unav.es/fcom/communication-society/en/resumen.php?art_id =568

García, J. y Heredero, O. (2015). Propuesta de un modelo genérico de análisis de la estructura de las narrativas transmedia. Icono 14, 13(2), 260-285. DOI:10.7195/ri14.v13i2.745

García-Noblejas, J. J. (1996). Comunicación y mundos posibles. Pamplona, España: Eunsa.

García-Noblejas, J. J. (2004). Resquicios de trascendencia en el cine: 'Pactos de lectura' y ‘segundas navegaciones' en las películas. En R. Jiménez \& J. J. García-Noblejas (Eds.) Poetica É Cristianesimo (pp. 29-70). Roma, Italia: Edusc.

Garrido, P. y Fernández, P. (2014). Branded Content \& Storytelling: la distancia más corta entre dos personas es una historia. En S. Liberal et al. (eds.): Últimos estudios sobre publicidad (pp. 35-48). Madrid, España: Editorial Fragua.

Guerrero, M. (2014). Webs televisivas y sus usuarios: un lugar para la narrativa transmedia. Los casos de "Águila Roja” y "Juego de Tronos” en España. Comunicación y Sociedad, 21, 239-267. Recuperado de https://dialnet.unirioja.es/servlet/articulo?codigo $=5301800$

Khan, N. (2012). Cutting the Fashion Body: why the Fashion image is no longer still. Fashion Theory, 16(2), pp. 235-249. DOI:10.2752/175174112X13274987924177

Leese, E. (1991). Costume Design in the Movies. New York, EE.-UU.: Dover Publications.

Martínez, G. (2017). Marketing y comunicación de moda. Madrid, España: ESIC Editorial.

Méndiz, A. (1988). La imagen de la mujer en la publicidad televisiva. En E. López-Escobar y

J. L. Orihuela (Eds.), La responsabilidad pública del periodista (pp. 87-102). Pamplona, 
España: EUNSA.

Méndiz, A. (2005). Una ética olvidada: Publicidad, Valores y Estilos de Vida. En Fundación COSO (Ed.), Información para la paz. Autocrítica de los medios y responsabilidad del público (pp. 61-84). Valencia: Ed. Fundación COSO.

Méndiz, A. (2007): Nuevas formas publicitarias: patrocinio, product placement y publicidad en Internet. Málaga, España: SPICUM (3 $3^{\mathrm{a}}$ ed).

Méndiz, A. y García, I. (2017). La hibridación de narrativas (transmedia y branded content) en el actual storytelling publicitario. En E. de la Cuadra (ed.). Nuevas narrativas. Entre la ficción y la información: desde la desregulación a la integración transmedia (pp. 343-356). Barcelona, España: UAB - Servei de Publicacions.

Núñez, M., Olarte, C. y Reinares, E. (2008). Influencia de la publicidad en las tendencias sociales: Una aproximación exploratoria al mercado publicitario español. En J. Pindado y G. Payne (Coords.). Estableciendo puentes en una economía global (pp. 1-19). Madrid: ESIC. Recuperado de https://dialnet.unirioja.es/servlet/articulo?codigo $=2739138$

Pollay, R. (1983). Measurind the Cultural Values Manifest in Advertising. En J. H. Leigh \& C. R. Martin (Eds.). Current Issues and Research in Advertising (pp. 71-92). Michigan, EE. UU.: University of Michigan.

Pollay, R. (1986). The Distorted Mirror: Reflections on the Unintended Consequences of Advertising. Journal of Marketing, 50(2), 18-36. DOI: 10.1353/asr.2000.0012.

Pollay, R. y Gallagher, K. (1990). Advertising and Cultural Values: Reflection in the Distorted Mirror.International Journalof Advertising,9(4),359-372. DOI: 10.1080/02650487.1990.11107165

Quevedo, M. (2016/07/05). TOUS Tender Stories. Universal Media. Recuperado de: https:// www.umww.com/um-spain/news/2016/07/tous-tender-stories

Ramos, M. y Pineda, A. (2009). El advertainment y las transformaciones de los formatos en el ámbito publicitario: el caso de los fashion films. Trípodos Extra, 2, 729-737. Recuperado de http://bit.ly/1FI5kPZ.

Ricoeur, P. (2010). Time and narrative. Volume 3. Chicago, EE.UU.: University of Chicago Press.

Rodríguez, M. I.; Paíno, A. y Ruiz, Y. (2017). Cambios en los modelos persuasivos: la nueva publicidad en tiempo real a través de estrategias narrativas transmedia. Estudio de caso de la campaña publicitaria de Tous, Tender Stories. adComunica, 14, 27-50. Recuperado de http://www.adcomunicarevista.com/ojs/index.php/adcomunica/article/view/41 1

Scolari, C. (2013). Narrativas Transmedia. Barcelona, España: Deusto.

Shao, A.; Raymond, M..A. \& Taylor, C. R. (1999). Shifting Advertising Appeals in Taiwan. Journal of Advertising Research, 39(6), 61-69. Recuperado de https://dialnet.unirioja.es/servlet/articulo?codigo $=475570$

Srikandath, S. (1992). Cultural Values Depicted in Indian Television Advertising. Gazzete, 48(3), 165-176. DOI: 10.1177/001654929104800302.

Uhlirova, M. (2013). 100 years of the Fashion film: Frameworks and Histories. Fashion Theory, 17(2), pp. 137-157. DOI: 10.2752/175174113X13541091797562.

Wang J. (1997). Through the Looking-Glass of Foreign Ads in China. Asian Journal of Communication, 7(1), pp. 19-42. DOI: 10.1080/01292989709388296 